\title{
THE INTERACTION OF ELECTRICAL ACTIVITY AMONG NEURONS OF LOBSTER CARDIAC GANGLION
}

\author{
AKIRA WATANABE* \\ Department of Physiology, Tokyo Medical and Dental University, Tokyo
}

The cardiac ganglion of the spiny lobster is known to produce periodic bursts of discharges even when it is completely isolated from the surrounding myocardial tissues (16). Each burst is composed of spikes originating from individual neurons in the ganglion. Each neuron fires more than once in a burst and generates a periodic train of spikes. These trains of individual cells are synchronized and form the periodic burst (17). On the other hand it has been shown by Matsui (16) that a slow oscillatory potential change is produced in this material, on which the bursts of spikes are superimposed. Similar slow potentials associated with spikes have been recorded in the heart ganglion of Limulus by several authors $(6,12,20)$. Prosser (20) suggested that the slow potential was the manifestation of the "synchronized force" of the activity of individual neurons.

Recently the intracellular recording technique was successfully applied to the neurons in the cardiac ganglion of the lobster by Hagiwara and Bullock $(9,10)$. They showed that all of the five large cells and some of the four small cells in the heart ganglionic trunk were "follower," namely they received impulses from presynaptic fibers and responded with summated synaptic potentials from which postsynaptic spikes arose. Under normal conditions the pacemaker was located in small cells which sent trains of impulses into presynaptic fibers of the large cells.

The object of this work is to investigate the mechanism of interaction among large cells, especially in relation to the slow potentials. Two or three microelectrodes were used for the simultaneous potential recording in two or three large cells. It will be shown that the interaction among large cells mainly occurs through special "electrical connections" among large cells. The slow oscillatory potential was recorded from large cells under certain conditions, and the relation between the slow potential and the interaction among cells was also found which will be described below.

\section{MATERIAL AND METHOD}

The experiments were performed on the Japanese lobster (Panulirus japonicus) of about $300 \mathrm{~g}$. The heart was exposed by removing a piece of the

Received for publication April 7, 1958.

*渡辺 昭 
dorsal carapace and then dissected out of the animal. The ganglionic trunk was isolated from the myocardium by the use of two needles with holders. The method for dissection was substantially the same as that described by Matsui (16). The muscle fragments were completely removed from the rostral portion of the trunk so as that at least four rostral large cells were visible without staining under the binocular microscope (magnification $40 \times$ ), while in the remaining portions the removal was not completely performed.

The structure of the heart ganglion in Panulirus japonicus resembles closely that of Palinurus vulgaris which was described in detail by Alexandrowicz (1), and diagramatically reviewed by Maynard (17). It contains five large and four small cells. They lie in a nervous trunk called the ganglionic trunk. The trunk does not bifurcate in this material. The large cells are placed in one line in the rostral half of the trunk In the present paper each of the large cells will be referred to as $\mathrm{L} 1, \mathrm{~L} 2 \ldots, \mathrm{L} 5$, respectively from rostral to caudal. L1 and L2 are close to each other, and in many preparations they are found to be in contact with each other. Distances between L2 and L 3 and between L 3 and L 4 are relatively large. The distance between L 4 and L5 is the largest, usually amounting to from 3 to $5 \mathrm{~mm}$. These cell bodies have an oval shape and are so large that they can be seen even with the naked eye when the staining is made with methylene blue.

The isolated ganglionic trunk was placed, as shown in fig. 1, across three pools of artificial sea water on three pieces of glass plates, separated by two air gaps. The isolated ganglionic trunk was placed so as that the central pool contains four rostral large cells. Since the distance between L4 and L5 was about $3-5 \mathrm{~mm}$., the L5 cell was placed in a side pool across the air gap of about $2 \mathrm{~mm}$. in width. A part of the trunk, which contains only axons between

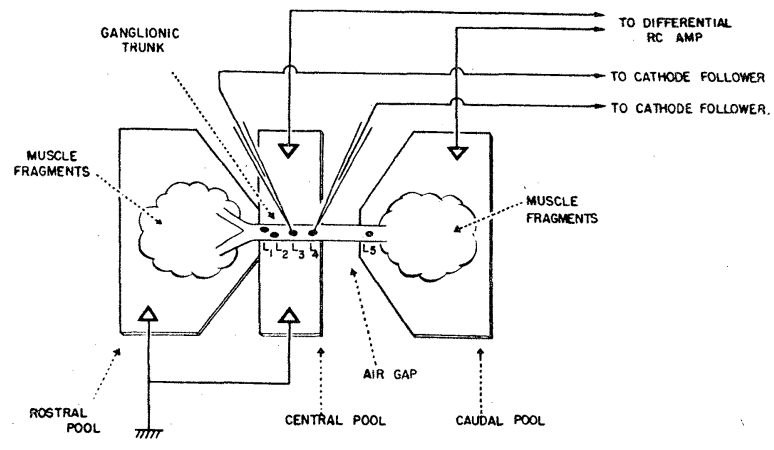

FIG. 1. General arrangement. The ganglionic trunk of the lobster heart is laid on three pools of artificial sea water. The central pool contains four large cells, whereas the caudal pool contains the fifth large cell (L5) and the four small cells. The central pool and the caudal pool are separated by an air gap of about $2 \mathrm{~mm}$. Axon impulses are recorded across this air gap with the aid of two silver-plate electrodes. The rostral pool and the central pool are usually kept contact and grounded. Intracellular recording is made from the four large cells in the central pool with the aid of capillary microelectrodes. 
L 4 and L5, was then exposed to the air. Under such conditions the conduction of the impulse in the axons was not blocked for several hours. This is probably due to the thick layer of connective tissue around the axons which prevents them from drying. External recording of impulses or external stimulation was performed with a pair of silver plate electrodes placed in each of the pools separated with this air gap. On some occasions the recording was also made across the other air gap, however in most experiments it was eliminated by bringing the side pool into contact with the central pool, as shown in fig. 1. The central pool was grounded with a chlorided silver plate electrode covered with moist cotton. The electrical activities of the individual nerve cells were recorded with the aid of intracellular capillary microelectrodes with external tip diameters of less than $0.5 \mu$ and filled with $3 \mathrm{~m}-\mathrm{KCl}$. Both the microelectrodes and the cathode-follower input stages were similar to those described by previous authors (e.g. (11)). In some experiments three microelectrodes with respective cathode-followers were simultaneously used to observe the potential changes from three different cells. Since the recording was made on a dualbeam oscilloscope, it was necessary that two outputs of the cathode-followers were selected out of three, to connect them to the two inputs of the oscilloscope. For this purpose two rotary switches were inserted between the cathodefollowers and the inputs of the oscilloscope.

In some experiments a polarizing current was made to pass through the cell membrane with another microelectrode. The current pulse was supplied with a square pulse generator through a resistance of $2 \times 10^{8} \Omega$.

The composition of the artificial sea water used for the physiological saline was the same as described by Matsui (16). All experiments were carried out at room temperature of $20^{\circ}-25^{\circ} \mathrm{C}$.

\section{RESULTS}

\section{Spontaneous potential variations in the cells of intact trunk}

The general features of the potential variations recorded from inside the large cells of the cardiac ganglion of the Japanese lobster resembled closely those obtained from the American spiny lobster, Panulirus interruptus (10). The value of the resting potential ranged between 70 and $50 \mathrm{mV}$, although the lower values were often obtained from materials under poor conditions. Longlasting potential variations appeared spontaneously which were periodically interrupted with silent periods (fig. $2, B$ ). Each continuous group of potential changes will be called an internal burst. The internal burst appeared synchronously with the burst of impulses recorded with external electrodes, thus with a frequency of from 0.5 to 1 per second and with a duration of up to $1.5 \mathrm{sec}$. Each internal burst was composed of relatively slow potential changes, each of which had a rising phase of about $8 \mathrm{msec}$, a peak value of $3-5 \mathrm{mV}$ and a slow declining phase of $20-30 \mathrm{msec}$. half time. These potential changes were superimposed and, with occasional spikes, formed an internal burst. These relatively slow potentials were interpreted by Hagiwara and Bullock (10) as synaptic potentials, as an impulse, presumably a presynaptic spike, was always recorded externally antecedent to each of them. This finding was confirmed 
in this work (fig. 2, A). The pattern most commonly obtained from the large cells was thus the type "follower" and the type "follower with spontaneity" was rarely encountered.

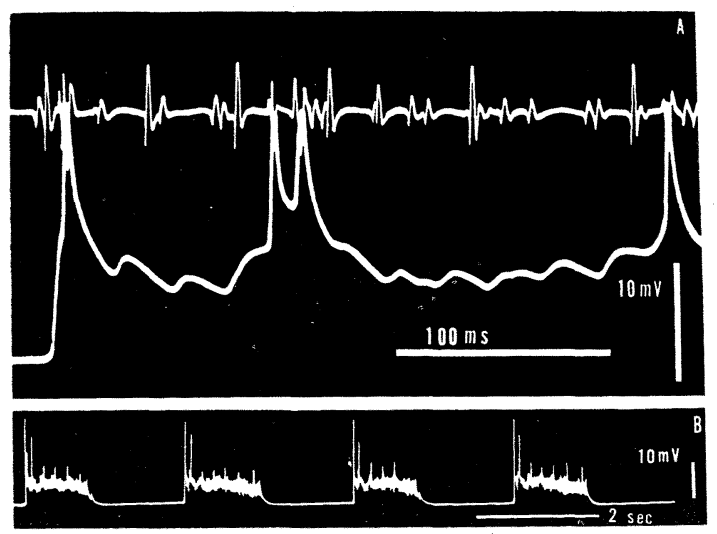

Fig. 2. $A$ : Similtaneous recordings of the axon impulses (upper beam) and the potential variations inside the second cell (lower beam). Spontaneous variations. Initial part of a burst is shown. On the lower beam synaptic potentials appear repeatedly and are summated. Spike potentials are occasionally made their appearance on the summated synaptic potentials. Each synaptic potential is preceded by a presynaptic impulse which is seen on the upper beam.

$B$ : Spontaneous potential change recorded from inside the fourth cell on the slower time base.

\section{Simultaneous recordings from two large cells}

Two microelectrodes were inserted into two adjacent large cells and the potential variations of these cells were recorded simultaneously. The examples are presented in fig. 3. It will be seen that the synaptic potentials in adjacent cells are highly synchronized. This fact seems to indicate that the large cells receive common presynaptic fibers. This is consistent with the finding that only a few could be identified as the presynaptic spikes in the surface recording. When the ganglionic trunk was stimulated across the air gap, a synaptic potential appeared in one of the large cells (10). It was found in one experiment that the threshold for synaptic potentials in L2 and L3 were strictly equal. Even under the finest control in stimulus strength the synaptic potentials in the two cells appeared strictly at the same intensity. This supplies a further evidence for the existence of common presynaptic fibers.

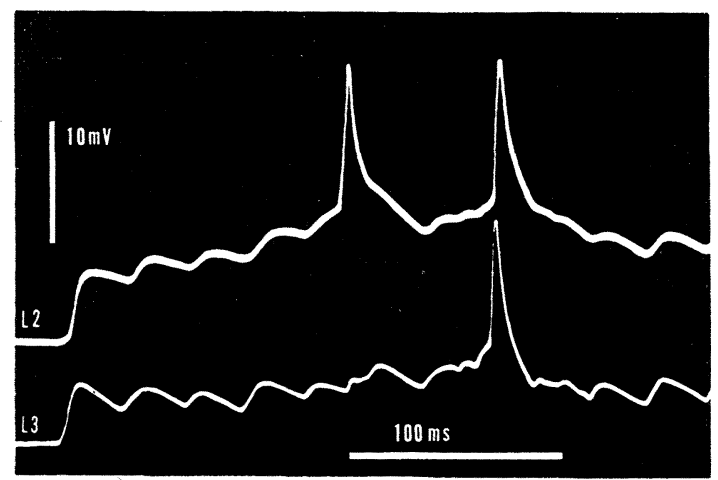

FIG. 3. Spontaneous potential variations recorded from inside the second (L2) and the third (L 3) large cells simultaneously. The initial part of an internal burst is shown. The synaptic potentials are highly synchronized between neighbouring cells, but the spikes are not always synchronized. 
In contrast with the synaptic potentials the spikes were not always synchronous among different cells.

\section{The anodal polarization}

The change of the membrane potential was recorded when anodic current was applied to the cell membrane with the use of a current electrode. The current pulse used had a duration of about $300 \mathrm{msec}$. and intensities were usually of the order of $10^{-8} \mathrm{~A}$. When the pulse was interpolated during the pause between the bursts the potential change caused by an anodic current was a hyperpolarization which attained to the final level within about $200 \mathrm{msec}$. The ratio of potential to the current at the final level (the effective resistance) was about $1 \mathrm{M} \Omega$, which was not inconsistent with that obtained from American lobster (19). The rise of the electrotonic potential did not always show a simple exponential time course. This indicates that the simple leaky capacitance cannot be adopted as an equivalent circuit for the membrane between the inside and the outside of the cell. This is consistent with the observation that the polarizing current flows through the neighbouring cell membrane as will be described later.

When a polarizing current was applied during a burst, a hyperpolarization was also observed, although the shape and the magnitude were obscured by non-reproducible potential variations superimposed on it (fig. 4). The number of spikes was diminished during the current application, and with sufficiently strong current all spikes disappeared. This indicates that the spikes are induced with depolarizations caused by the superposition of synaptic potentials.

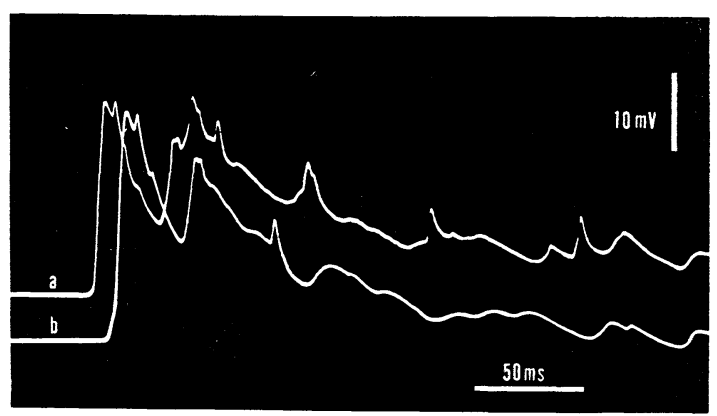

FIG. 4. The effect of current application on the spontaneous poiential variations recorded from inside the second large cell. A recording and a polarizing electrode are inserted into the cell. The initial part of a spontaneous burst is shown.

$a$ : Without polarization. Small spikes are superimposed on summated synaptic potentials.

$b$ : Inward current of $1.6 \times 10^{-8} \mathrm{~A}$ is applied to the cell membrane. The resting level is lowered by about $6 \mathrm{mV}$. Small spikes are decreased in number.

The level at which the spike started was not constant. In some examples it was found that the spikes started from under the resting level. This seems to indicate that the originating point of the spike is, at least in some instances, not at the membrane of the cell soma but at a region at some distance away from the cell soma. This conclusion agrees with those of other authors $(7,10)$.

The synaptic potential did not disappear with anodic current. On the contrary it was revealed by strong current application that the size of the synaptic potential was increased with the increase of the resting potential (fig. 5). In a few examples the amplitudes of the synaptic potentials were plotted against the membrane potential, and it was found that the former was 
roughly proportional to the latter. This suggests that the nature of the synaptic potentials in the cardiac ganglion resembles that of the end-plate potential in vertebrate muscle (8). At least some of the synapse must be located in the adjacent region of the cell soma, because this proportionality can be expected only when the recording is made at the focal point of the synaptic potential.
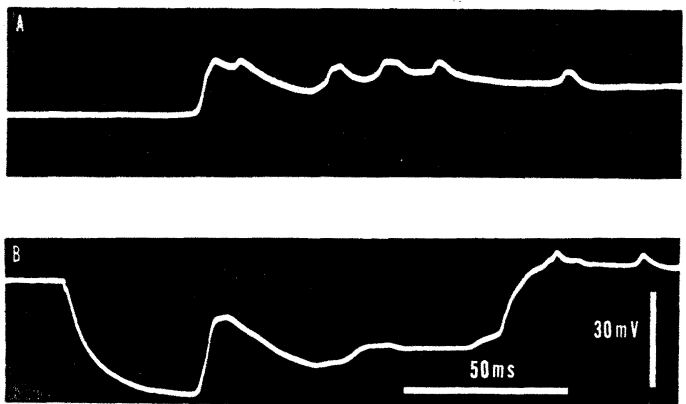

FIG. 5. The effect of current application on the spontaneous potential variation, with lower amplification and stronger current than in records in fig. 4. The second large cell.

$A$ : Without current application.

$B$ : Inward current of $1.5 \times 10^{-7}$ $A$ is applied. The synaptic potential is increased in amplitude, and the superimposed small spikes are abolished.

\section{Cathodal polarization}

When the polarizing current was applied outwardly through the membrane depolarization occurred and with sufficient intensity a series of spikes appeared. In most cases the amplitudes of these spikes measured from the level of electrotonic potential were very small $(2-4 \mathrm{mV})$ and were comparable with the amplitudes of spikes which were superimposed on the synaptic potential. Less frequently larger spikes were also elicited (fig. 6). Those spikes were usually preceded by clear steps which survived even when the main spikes had dropped out. The spikes were repeated during the flow of current. The threshold current was of the order of $10^{-8} \mathrm{~A}$.

The electrical connections among large cells

Two microelectrodes were inserted into one of the large cells, one serving for polarizing the cell membrane and the other for recording the change of the membrane potential caused by polarization. As described in the previous section, application of anodic current produced an increase in the membrane potential or a hyperpolarization of the cell membrane. When the membrane potential of one of the remaining large cells was recorded simultaneously by using the third internal microelectrode, a similar in-

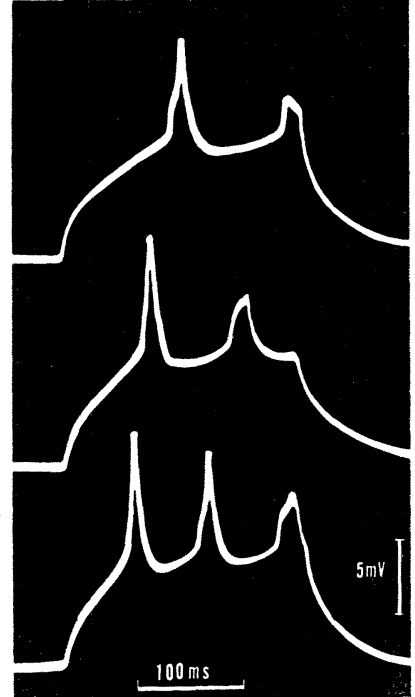

$\therefore$ FIG. 6. The effect of outward current applied to the third large cell. The current intensity is increased from upper to lower. crease in the membrane potential was always observed in the second cell, in which no current electrode was inserted. In examples presented in fig. 7 , the 
first cell was L3 while the third electrode was inserted into L4, located at a distance of $380 \mu$ from L3. In this case the final value of the hyperpolarization was $7.9 \mathrm{mV}$ in the first cell. The corresponding value of hyperpolarization in the second cell was $3.8 \mathrm{mV}$, which was smaller than that of the first cell. Besides the attenuation of the final steady value a slower rate of development was always observed in the hyperpolarization of the second cell.
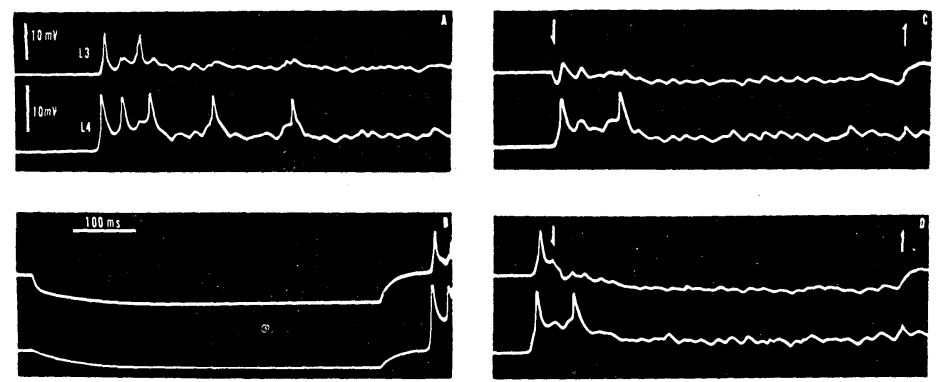

FIG. 7. The electrotonic potentials produced in two apparently separate large cells, into one of which (the third large cell) the current electrode is inserted.

Upper beam: Potential variations inside the third large cell (L 3).

Lower beam: Potential variations inside the fourth large cell (L4).

In $C$ and $D$, the on-point and the off-point of the polarizing current are indicated by a downward directed and an upward directed arrows respectively.

$A$ : Without current application. The initial part of the spontaneous burst is shown.

$B$ : An inward current pulse is applied through the current electrode inserted into L 3. Being associated with an electrotonic potential developed in L 3, a smaller, slowly developed electrotonic potential appears in L4.

$C$ : The polarizing current is applied during the burst.

$D$ : The polarizing current is applied at a later stage of the burst.

When the cathodic current was applied to the first cell, the depolarization occurred in the first cell as well as in the second cell, and the amplitude of the depolarization in the second cell was smaller than that in the first cell. Thus the general feature of the phenomenon was similar to the case of anodic polarization, except that the depolarization elicited spikes when the current was strong enough.

Approximately similar results were obtained with the combination of L1 and $\mathrm{L} 2, \mathrm{~L} 2$ and $\mathrm{L} 3$, and of $\mathrm{L} 3$ and $\mathrm{L} 4$.

The foregoing results indicate that the potential change observed in the second cell is an electrotonic spread from the first cell. This conclusion suggests the presence of protoplasmic connection among large cells of the present ganglion. Even though the morphological basis of this supposition is not yet clear, it is very likely. The presence of the thick layer of connective tissue covering the ganglionic trunk seems not responsible for this phenomenon, because when the recording electrode was just outside the cell but still inside the layer of connective tissue no appreciable potential change was recorded either in the first cell or in the second cell even when the intensity of the current was 
strong enough to produce a hyperpolarization of several millivolts in both of the cells.

If the spreading of electrotonic potentials among large cells does exist, the next problem raised is whether a spike conducts among cells or not. In fig. 2 and in fig. $7 \mathrm{~A}$, it is shown that spikes of one cell are not always associated with those of the other cell. This indicates that if the conduction of spikes takes place between two large cells the safety factor of the conduction is very low.

Further it must be noticed that those asynchronous spikes are not associated even with any corresponding electrotonic spread in neighbouring cells. Therefore it is concluded that the electrical connection among large cells permits the spread of the potential change of a relatively slow time course such as that produced by a long current pulse, but barely permits the spread of the spike component. This seems to be due to the electrical characteristics of the connection. As stated above, the electrotonic potential developed in the second cell has a retarded time course. In fig. $7 B$ the electrotonic potential developed in $\mathrm{L} 4$ has a half time of about $45 \mathrm{msec}$. Accordingly, the ratio of the amplitude of electrotonic potential in L3 to that in L4, or the attenuation factor, depends on time from the beginning of the current. In order words, the attenuation factor is smaller for the electrotonic potential produced by a shorter current pulse. In the case of fig. 7 , the attenuation factor is 0.48 for a sufficiently long current pulse, 0.27 for a current pulse of $20 \mathrm{msec}$. duration, and 0.16 for a current pulse of $10 \mathrm{msec}$. duration. Therefore a spike of $6 \mathrm{mV}$ amplitude and $10 \mathrm{msec}$. duration in the first cell will produce a potential change of only $1 \mathrm{mV}$ in L3, which is barely recognizable on the present records. The above results indicate that the characteristic function of the connection is the transmission of slower components of the potential variations. In the "follower" type of responses, the synaptic potentials are summated and form a plateau which lasts for several hundred milliseconds. Such a rise of potential should spread from one cell to the other. This tends to equalize the level of the plateau among the large cells. Thus the similarity among potential changes of the large cells. is likely to be due to two main factors: the existence of common presynaptic fibers, and the electrical connection among large cells.

The problem remains whether the small cells also have protoplasmic connections with the large cells or not. No attempt has been made to insert microelectrodes into a small cell, but there is an observation which favours the existence of such a connection. During the course of polarization experiments, it was found that the appearance of a spontaneous burst showed a tendency to synchronize with the break of an anodic polarizing pulse, which was repetitively applied to one of the large cells with constant frequency. In fig. 8 is presented an analysis of one of such examples. The anodic current pulse was repeatedly applied to the cell L2 with the frequency of $0.43 / \mathrm{sec}$. The spontaneous beat frequency of $0.52 / \mathrm{sec}$. was changed to about $0.4 / \mathrm{sec}$. within the course of two or three polarizing pulses. The ordinate represents the interval between the off-point of the current pulse and the on-point of a spontaneous burst, while the abscissa represents the order of the applied pulses. Since the first current 
pulse was started at any phase of spontaneous burst, the first interval was accidental. However, as shown in fig. 8, the interval became about $600 \mathrm{msec}$. after application of two or three current pulses, and stayed at this value. This indicates that the polarizing current has a certain influence on the pacemaker region which usually has its seat in the small cells. The external field seems not responsible for this synchronism because the polarizing current was of the order of only $10^{-8} \mathrm{~A}$.

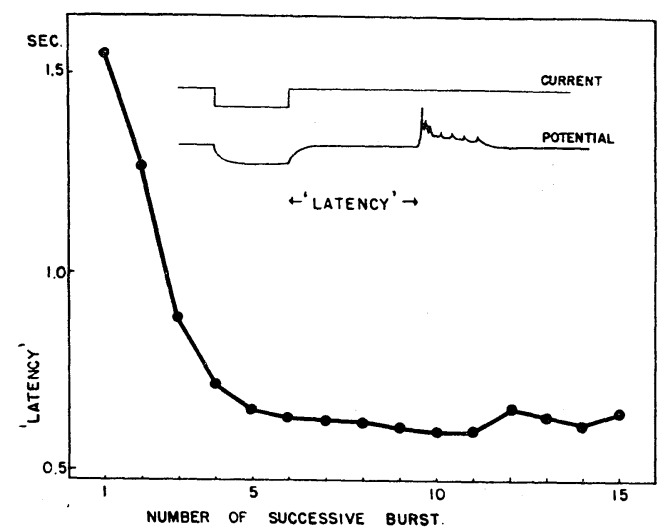

FIG. 8. The effect of periodic inward current pulse on the rhythm of the spontaneous burst. The anodic current pulse of about $7 \times 10^{-8} \mathrm{~A}$ was repeatedly applied to the 2 nd large cell with a frequency of 0.44 per second. When the repetitive current pulse application begins, the interval between the off-point of the current and the front of the burst ('Latency') is quickly changed.

\section{Slow oscillatory potentials}

According to Maynard (cited by Hagiwara and Bullock, 10) in a normal ganglionic trunk the small cells behave as the pacemaker and the large as followers. On the other hand Maynard (17) stated that the large units can fulfil pacemaker functions because they can maintain the burst without small neuron somata. These conclusions suggest that when the normal pacemaker in small cells is affected and the impulses from it are blocked, the other cells, which work normally as followers, can be substituted as the pacemaker, as in the case of the vertebrate heart ventricle.

It is of interest to study the potential change at the point where the periodic burst is generated. In order to increase the possibility of successful recording from such a point, the potential changes in two or three large cells were simultaneously recorded by using two or three internal microelectrodes. The procedure was to insert the microelectrodes into individual large cells, then to apply $0.1 \%$ procain-sea water to the caudal pool which contained the fifth large cell (L5) and small cells.

In most cases application of anaesthetics to small cells induced a tonic train of synaptic potentials in a large cell. After a while potential variations were in some specimens completely ceased. In others, however, a slow potential change was observed under this condition. An example shown in fig. 9 was obtained from L3. A slow oscillatory potential change was produced spontaneously, and a train of spikes was superimposed on its depolarized phase. This slow oscillatory potential occurred successively with the frequency of about 1 per sec. and the amplitude was not constant, ranging from a barely recognizable 
value to about $10 \mathrm{mV}$. Bullock and Terzuolo (7) also reported the same kind of oscillatory potentials.

Spread of slow oscillatory potentials among cells

In fig. 10, records are shown of slow oscillatory potentials associated with spikes obtained from L2 and L3 simultaneously. The slow potential in L2 (lower beam) followed after that in L3 (upper beam) with a reduced amplitude and with a certain delay. The ratio of the amplitudes was about 0.3 while the delay was about $100 \mathrm{msec}$. in this example.

It is likely that this synchronization is due to the presence of the electrical connection between the cells, because the order of magnitudes of delay in time course and reduction in amplitude agree with those observed in the polarization experiments. As described above the electrical characteristics of this connection are such that it allows the spread of slow potentials. Therefore it is concluded that the synchronization of the slow oscillatory potential among large cells is due to the existence of the electrical connections.

\section{DISCUSSION}

The foregoing results show that under certain conditions the large cells in the lobster heart ganglion generate an oscillatory slow potential changes, associated with spikes on their depolarized phase. Under normal conditions, however, the pacemaker is situated in a small cell or small cells, accordingly the pacemaker located in the large cells should be regarded as an abnormal phenomenon and is analogous to the
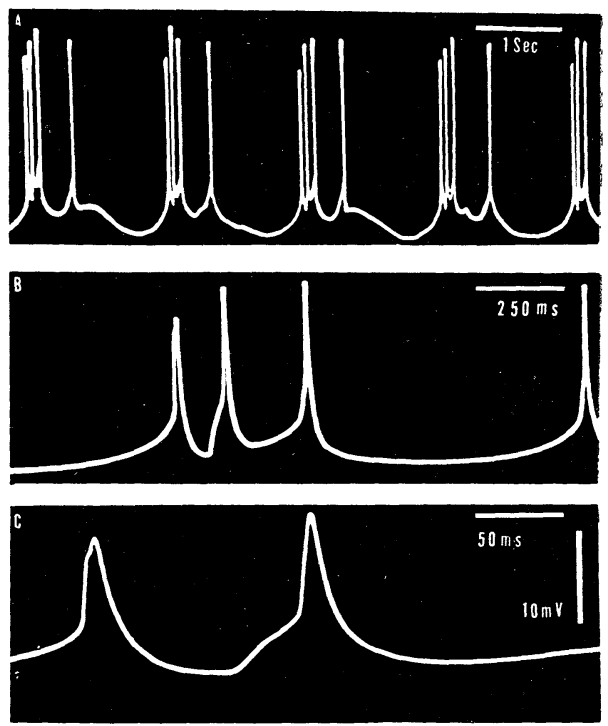

FIG. 9. Slow oscillatory potential changes with superimposed spikes recorded from inside the third large cell. The small cells and the fifth large cell are anaesthetized with $0.1 \%$ procain-sea water. Successive records at three different sweep speeds are presented.
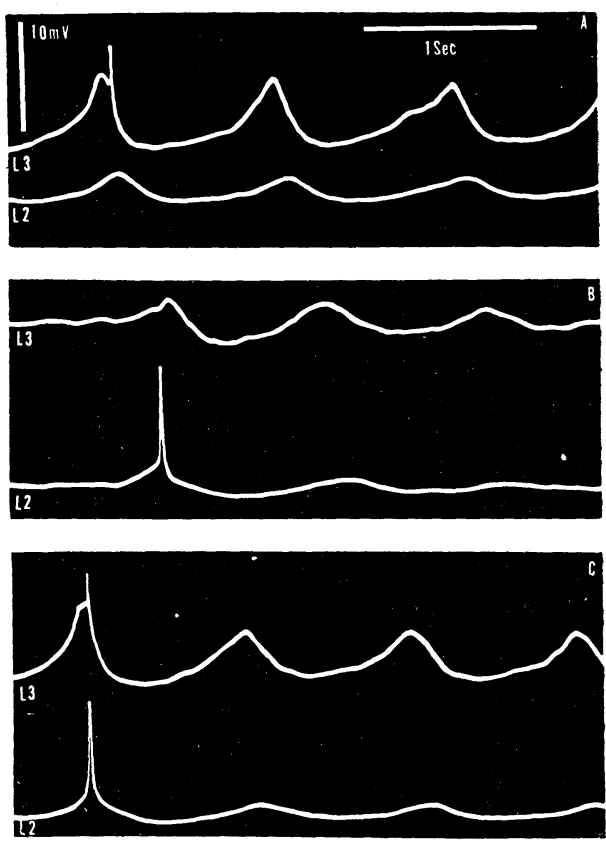

FIG. 10. Spread of the slow oscillatory potential among large cells. Small cells and the fifth large cell are anaesthetized with $0.1 \%$ procain-sea water. Simultaneous recordings from the second ( L 2) and the third (L3) large cells. 
"ventricular automaticity" in a vertebrate heart. Although the present experiments provide no direct evidence on the events in the normal pacemaker, it is likely that a similar mechanism is responsible even for the initiation of the periodic burst in the normal pacemaker.

Similar slow oscillatory potential changes have been recorded with the external electrodes in the heart ganglion of Limulus $(6,12,20)$, in the heart ganglion of lobster (16), and in the cardiac muscle of snails (2) and of vertebrates (4). Similar oscillations were also obtained from other tissues besides hearts, for example, from the ureter or the intestine of the mammals (3) and even from a plant cell, Nitella (18). It is conceivable that the slow oscillatory potential presented in this paper corresponds to some of the slow potentials recorded with external electrodes. It is also very probable, however, that certain potential variations of different natures, e.g. summated synaptic potentials, might be confused in the same category.

Arvanitaki (2), Hodgkin and Rushton (14), and Hodgkin (13) reported a kind of oscillatory potential developed in non-medullated axons. Brink, Bronk and Larabee (5) also recorded a conspicuous oscillation found in axons in decalicified solution. These oscillations had, however, far higher frequencies than the oscillations presented in this paper.

The slow oscillatory potentials developed in the lobster cardiac ganglion have several distinct properties which make it appear very unlikely that they are a sort of a spike potential.

i) The amplitudes of the individual oscillations vary widely from barely recognizable value to about $10 \mathrm{mV}$. If these slow oscillations were to be regarded as a sort of a spike potentials, it might be expected that successive oscillations would be equal in size, at least approximately, because ordiary action potentials have an all or none property which is approximately applicable to the spike potentials recorded even at the site where it originates.

ii) In the simultaneous records of slow potentials from two or three large cells, it was never found that the lagging slow potential had a larger amplitude than the leading. Apparently the slow potentials conduct from one cell to another decrementally. In other experiments, however, it was shown that the electrotonic potential also "conducts" between cells with a certain reduction in final value and in rate of rise, even when the sense of the polarizing current was inward to the membrane and consequently the membrane was hyperpolarised. This indicates that the "conduction" of the slow oscillatory potential is simply explicable as an electrotonic spread. There is no available evidence indicating that the slow oscillatory potential conducts actively, similar to spike potentials of other systems, which conduct by stimulating adjoining regions and cause regenerative depolarization. Further it must be noticed that the slow oscillation has no inflection in its rising phase except for the transition point to the superimposed spike. The inflection is often regarded as the transition point from a local potential to a spike potential.

iii) Outward current supplied to the cell membrane does not produce the slow potential. On the contrary it was observed that a positive electrotonic potential is usually followed by a hyperpolarization. 
iv) Stimulation of the axon is also ineffective for the initiation of the slow potential and only causes an antidromic action potential. In some preparations it was observed that repetitive stimulation inhibited the slow oscillatory potential. However the results were not constant.

All these facts seem to indicate that the slow oscillatory potential is a different type of a potential variation from the ordinary spike potential. Further the slow oscillatory potential is not explained as a result of disappearance of positive after-potentials of preceding spikes because the oscillation persists even when a preceding wave is not superimposed by a spike or spikes.

It seems at first surprising that the large cells are electrically connected with each other, since they are apparently separated by distances of several hundred microns. But once the throught is accepted that these cells form a sort of syncitium the results can be easily understood. This type of syncitium is, however, somewhat different in function from that of vertebrate cardiac muscle fibers, because the fast component of the potential seems not to conduct between cells. The electrical connection must have some bearing on the transmission of the slow potentials and consequently contributes to the formation of synchronized discharges of the different cells. This function of the slow potential was expected, though vaguely, by previous workers $(16,20)$, although these authors seemed to look for the well-known type of electrical interaction, described by Katz and Schmitt (15). This is, however, very different from that described in this paper. The electrical connection causes an interaction by spreading the electrotonic potential from one cell to another along channels, not through tissue fluid. On the other hand, Katz and Schmitt described that under certain conditions two completely disconnected axons are influenced mutually by means of the action current of one axon, a part of the current penetrating the membrane of the other axon. In the former the protoplasmic connections must be expected to be between cells, and only through them the lines of flow of the current can reach the membrane of adjacent cells. In the latter there is no protoplasmic connection and the effective action current must traverse the interstitial space to change the membrane potential of the adjacent cells. This difference in the arrangements of the local current means that, when the external medium is replaced with that of low conductivity, the effect of interaction will be decreased if the underlying process is that here reported whereas it will be increased if the process is like Katz and Schmitt's. The two processes are therefore quite distinct, although no attempt was made experimentally to decide between them by the above idea. The conclusion was deduced from the observation that until current electrode penetrated the membrane of the first cell no potential change was observed in the membrane of the second cell, even if the current electrode was located just outside the first cell.

In nodal myelinated axons it is well known that the conduction takes place in a saltatory manner, in other words the action current flows through an inexcitable internodal distance and stimulates the next node of Ranvier (21). The electrical connection in the cardiac ganglion of the lobster and the internodal distance of myelinated fiber are not unlike in this respect. It is important, 
however, that these connections are found in apparently separated nerve cells. It is possible that this type of interaction is at play at some points in the central nervous system where the effects of synchronization are produced.

\section{SUMMARY}

1. The potential changes were recorded from the individual large cells of the lobster cardiac ganglion with the aid of intra-cellular microelectrodes. Special attention was paid to the interaction among the cells, and, using a dual beam oscilloscope, simultaneous recording was made from two different cells.

2. The "follower" type of potential was the most common and similar to that obtained in ganglion cells of an American lobster, described by Hagiwara and Bullock (10), and Bullock and Terzuolo (7).

3. The synaptic potentials in two adjacent cells were closely synchronized. This seems to indicate existence of common presynaptic fibers. On the other hand the superimposed spikes were not always synchronized.

4. With an inward current applied to the cell membrane, the spike generation was often blocked. On the other hand, however, the synaptic potentials were increased in amplitude.

5. An outward current applied to the cell membrane caused a depolarization. With sufficient strength a spike or a series of spikes was produced superimposed on the depolarization.

6. Electrotonic potentials were elicited by an applied current, not only in the cell in which the current electrode was inserted, but also in a neighboring cell in which no current electrode was inserted, with a reduced amplitude and a delayed time course. This phenomenon was regarded as existence of "electrical connections" among large cells.

7. In some specimens when the small cells were anaesthetized with $0.1 \%$ procain-sea water, a slow oscillatory potential change was produced in one of the large cells, which has variable amplitude of up to $10 \mathrm{mV}$ and frequency of about one per second, and was superimposed with a spike or a series of spikes.

8. The slow oscillatory potentials appeared in a neighboring cell with a certain phase shift and a reduced amplitude. This phenomenon was explained as a sort of electrotonic spread which is made possible by the electrical connection among cells.

I wish to thank Professor Y. Katsuki for constant encouragement and advice, and Dr. S. Hagiwara for his frequent valuable discussions. My thanks are also due to Professor K. Kato who has given me information about the anatomy on this material, and Dr. T. H. Bullock for reading the manuscript and making many constructive criticisms. A part of the expense of this work was supported by a grant from the Ministry of Education.

\section{REFERENCES}

1. Alexandrowicz, J. S. The innervation of the heart of the Crustacea. I. Decapoda. Quart. J. Micro. Sci. 75 : 181, 1932.

2. ARVANITAKI, A. Propriétés rythmiques de la matière vivante. Variations graduées la 
polarisation et rythmicités. Deuxieme partie. Paris: Hermann, 1938.

3. BOzLER, E. The activity of the pacemaker previous to the discharge of a muscular impulse. Am. J. Physiol. 136: 543, 1942.

4. Bozler, E. The initiation of impulses in cardiac muscle. Am. J. Physiol. 138: 273, 1943.

5. Brink, F., Bronk, D. W. And Larrabee, M. G. Chemical excitation of nerve. Ann. N. Y. Acad. Sci. $47: 457,1946$.

6. Bullock, T. H., BURR, H. S. AND NIMS, L. F. Electrical polarization of pacemaker neurons. J. Neurophysiol. $6: 85,1943$.

7. Bullock, T. H. AND Terzuolo, C. A. Diverse forms of activity in the somata of spontaneous and integrating ganglion cells. J. Physiol. 138: 341, 1957.

8. FATT, P. AND KATZ, B. An analysis of the end-plate potential recorded with an intracellular electrode. J. Physiol. 115: 320, 1951.

9. HAgiwara. S. AND Bullock, T. H. Study of intracellular potentials in pacemaker and integrative neurons of the lobster cardiac ganglion. Biol. Bull. 109: 341, 1955.

10. HAGIWARA, S. AND BULLOCK, T. H. Intracellular potentials in pacemaker and integrative neurons of the lobster cardiac ganglion. J. Cell. Comp. Physiol. 50: 25, 1957.

11. Hagiwara, S. AND Watanabe, A. The effect of tetraethylammonium chloride on the muscle membrane examined with an intracellular microelectrode. J. Physiol. 129: $513,1955$.

12. HeinbeCKer, P. The potential analysis of a pacemaker mechanism in Limulus polyphemus. Am. J. Physiol. 117 : 686, 1936.

13. Hodgkin, A. L. The local electric changes associated with repetitive action in a non-medullated axon. J. Physiol. 107: 165, 1948.

14. Hodgkin, A. L. AND Rushton, W. A. H. The electrical constants of a crustacean nerve fibre. Proc. Roy. Soc. B. 133: 444, 1946.

15. KATZ, B. AND SchmitT, O. H. Electric interaction between two adjacent nerve fibers. J. Physiol. $97:$ 471, 1940.

16. Matsui, K. Spontaneous discharges of the isolated ganglionic trunk of the lobster heart (Panulirus japonicus). Sci. Rept. Tokyo Kyoiku Daigaku B. 7: 257, 1955.

17. MAYNARD, D. M. Activity in a crustacean ganglion. II. Pattern and interaction in burst formation. Biol. Bull. 109 : 420, 1955.

18. Osterhout, W. J. V. AND Hill, S. E. Pacemakers in Nitella. J. Gen. Physiol. 22: $115,1939$.

19. OtANI, T. AND Bullock, T. H. Responses to depolarizing currents across the membrane of some invertebrate ganglion cells. Anat. Rec. 128: 599, 1957.

20. Prosser, D. L. Single unit analysis of the heart ganglion discharge in Limulus polyphemus. J. Cell. Comp. Physiol. 21 : 295, 1943.

21. TASAKI, I. Nervous transmission. Springfield: Charles C. Thomas, 1953. 